\title{
Royal Jelly Induced Anxiolytic Effects and Prevent Hot Flushes in a Menopausal Model on Wistar Rat
}

\author{
Djiogue Sefirin*1, Adjoffoin Chiara Nange ${ }^{1}$, Motoum Tedjo Florette ${ }^{1}$, Zemo Gamo Franklin ${ }^{1,2}$, \\ Awounfack Charline Florence ${ }^{1}$, Kamtchouing Pierre ${ }^{1}$ and Njamen Dieudonné ${ }^{1}$ \\ ${ }^{1}$ Laboratory of Animal Physiology, Department of Animal Biology and Physiology, Faculty of Science, Cameroon
}

${ }^{2}$ Department of Psychology, Faculty of Arts, Letters and Social Sciences, Cameroon

*Corresponding author: Sefirin Djiogue, Department of Animal Biology and Physiology, Faculty of Science, University of Yaounde

I, P.O. Box 8069, Yaounde-Cameroon

\begin{abstract}
ARTICLE INFO
Received: 慧 July 09, 2019

Published: 蔧 July 19, 2019

Citation: Djiogue S, Adjoffoin Chiara N, Motoum Tedjo F, Zemo Gamo F, Awounfack Charline F, Kamtchouing P, Njamen D. Royal Jelly Induced Anxiolytic Effects and Prevent Hot Flushes in a Menopausal Model on Wistar Rat. Biomed J Sci \& Tech Res 19(5)-2019. BJSTR. MS.ID.003356.
\end{abstract}

Keywords: Royal Jelly; Anxiolytic Effects; Hot Flushes; Ovariectomy; Menopause

\begin{abstract}
Royal Jelly (RJ) is a creamy liquid secreted by bees for the nutrition of their larvae and the queen bee. Previous work has shown that RJ can bind to estrogen receptors and brings about the same effects as that of estrogens. The aim of this study was to evaluate the effects of RJ on menopause related anxiety and on hot flushes in Wistar rat. To do this, the Elevated Plus-Maze (EPM) and the Open Field (OF) test were used to evaluate the anxiolytic effects of royal jelly, while data loggers were used in the case of hot flushes. SHAM and OVX groups received distilled water. Three doses of RJ were tested $(100,200$ and $300 \mathrm{mg} / \mathrm{kg} \mathrm{BW})$. Diazepam and estradiol valerate were used as reference drug. All the substances were administered per os, except diazepam(i.p.). As results, Royal jelly induced a significant increase $(p<0.01, p<0.001)$ of the number of rearing and head dipping in the EPM test compared to OVX group. It also induced a significant decrease $(\mathrm{p}<0.05, \mathrm{p}<0.01, \mathrm{p}<0.001)$ of the weight of faeces produced and the rectal temperature in the EPM. In the OF test, compared to OVX group, RJ significantly increased $(p<0.05, p<0.01)$ the centre square time and the number of rearing. It also induced a significant decrease of the number of grooming. The evaluation of hot flushes showed that, comparing with the OVX group, RJ led to a decrease in the total number as well as the frequency of hot flushes at all the doses tested compared to OVX group. These results suggest that royal jelly is capable of reversing some disorders related to estrogen depletion induced by ovariectomy. These anxiolytic effects and hot flushes prevention of royal jelly could justify it traditional use by women facing menopause.
\end{abstract}

\section{Introduction}

Menopause also known as the climacteric at short term, is the time in women lives when menstrual period stops permanently [1]. At a physiological level, menopause happens because of a cessation in ovarian hormones [2]. This decrease in ovarian hormones is responsible for some physiological disorders which include vasomotor disorders (night sweats and hot flushes), mood changes [3], anxiety and irritability. Statistically, $10 \%$ of the world population suffer from several forms of anxiety [4] and $51 \%$ of these are menopausal women [5]. In the same light, $80 \%$ of menopausal women suffer from hot flushes [6]. These menopausal disorders affect the social life, sexual life, and increase morbidity in women. The first approach of treatment of anxiety was the use of benzodiazepines; a group of anxiolytic drugs that modulate
GABAA receptors but failed due to its secondary effects like muscle relaxation and sedation. However, these psychotropic agents seem not appropriate for the primary treatment of symptoms associated to a lack of estrogens [7]. Hormone Replacement Therapy (HRT) is also commonly used for the treatment of physiological disorders observed in menopausal women [8]. Despite the effectiveness of hormone replacement therapy to alleviate menopause symptoms, it is associated with high risk of cancer and cardiovascular diseases $[9,10]$. Following this, the needs for developing new alternative treatments for the management of physiological and/or psychological disorders related to menopause remain urgent [11]. Royal Jelly (RJ) is a yellowish white creamy liquid secreted by nurse bees (Apismellifera L) [12]. It serves as food for honey bee larva 
during their maturation process and it is the specific food given to the queen for her whole lifespan. Royal jelly is one of the most effective and beneficial remedy for human being, as it is widely used both in folk and in modern medicine and as a dietary supplement [12]. Previous work has shown that RJ can bind to oestrogen receptors and brings about the same effects as that of estrogens [13]. Royal Jelly shown many pharmacological activities such as antioxidant, neurotropic, hypoglycemiant, hypocholesterolaemiant, hepatoprotective and nephroprotective [12]. Nevertheless, there are no previous report on the effects of royal jelly on anxiety and hot flushes. Therefore, the aim of this study was to evaluate the effects of royal jelly on menopause related anxiety and on hot flushes in ovariectomised Wistar rat.

\section{Material and Methods}

\section{Animals}

The experiments were carried out with juvenile female Wistar rats weighing between $150 \pm 10 \mathrm{~g}$ and aged between 10 and 14 weeks. The animals were housed in room supplied with day light (temperature $25^{\circ} \mathrm{C}$; humidity 50-80\%; $12 \mathrm{~h}$ light-dark cycle). They had free access to a standard soy-free rat diet and were provided with tap water ad libitum. Animal handling conditions were in accordance with the guidelines of the institutional Ethic Committee of Cameroon's Ministry of Scientific Research and Technological Innovation, which equally adopted the guidelines established by the European Union on Animal Care (CEE Council 86/609; Reg. no.FWA-IRD0001954).

\section{Substance Tested and Determination of Doses}

The substance tested in this study was royal jelly ("GELEE ROYAL BIO") provided by "PLANETE AU NATUREL" / France. The doses of administration were prepared based on the prescription on the box (14.3 mg/kg BW for human); the equivalent doses in rat were extrapolated from this human dose, to afford $100 \mathrm{mg} / \mathrm{kg} \mathrm{BW}$. To obtain a dose response curve of the substance, 2 other doses (200 and $300 \mathrm{mg} / \mathrm{kg} \mathrm{BW}$ ) were generated.

\section{Chemicals}

Diazepam (Valium ${ }^{\circledR} 10 \mathrm{mg} / 2 \mathrm{ml}$, Laboratoire Roche, Fontenaysous-bois, France) and estradiol valerate (Progynova® 2mg, DELPHARM, Lille, France) were used as reference drugs.

\section{Setting of Data Loggers}

The data loggers used were calibrated in a computer having the "ACR smart button". They were programmed to take temperatures every 2 minutes, 6 hours before the beginning of treatment till the end. These data loggers were robed with paraffin and inserted into the abdominal cavity of the rats during operation. This was done under anesthesia induced with Valium and ketamine respectively through the intraperitoneal pathway at the doses of 10 and 50 $\mathrm{mg} / \mathrm{kg}$ BW respectively. After insertion, the abdominal cavity was sutured.

\section{Experimental Design}

All female Wistar rats were ovariectomized before each test except the SHAM group. The bilateral operation was done using the dorsal approach [14] under diazepam and ketamin anaesthesia (10 and $50 \mathrm{mg} / \mathrm{kg}$ BW respectively; i.p.). After 14 days of endogenous hormonal decline [15], animals were randomly distributed into different groups: SHAM operated and negative control (OVX) groups received distilled water; E2V and DZP groups received estradiol valerate and diazepam respectively at the dose of $1 \mathrm{mg} / \mathrm{kg}$ BW each; and three others groups received royal jelly at the doses of 100, 200 and $300 \mathrm{mg} / \mathrm{kg}$ BW (RJ100, RJ200 and RJ300). All substances were dissolved in distilled water (vehicle) and were administered per os (1 mL/100 g BW for oral administration), except diazepam (i.p.).

For behavioral assessments, the experiment was carried out in a calm room supply with day light after an acclimation period of three days in this room. The parameters were registered with a video-camera system. After each test, the apparatus was cleaned with $70 \%$ ethanol solution and dry cloth before placing the next animal, to avoid perturbation by faeces or urine of the previous animal.

Elevated Plus-Maze Test: The Elevated Plus-Maze (EPM) is a test for measuring anxiety-like behavior in rodents. The test is based on the natural aversion of rodents for open and elevated areas and on their natural spontaneous exploratory behavior in new environments. The maze is made up of two opposite open arms $(50 \mathrm{~cm} \times 15 \mathrm{~cm})$, crossed with two enclosed arms of the same dimensions with walls $50 \mathrm{~cm}$ high. The arms are connected with a central square, $15 \mathrm{~cm} \times 15 \mathrm{~cm}$ to give the apparatus a plus sign appearance. The maze was elevated $71 \mathrm{~cm}$ above the floor.

In this experiment, 49 female Wistar rats were used and there were distributed into seven groups (as listed above) of seven rats each. One hour after the administration of the different substances, the animals were placed in the centre of the EPM and observed for five minutes each. For each rat, the following parameters were taken: Time spent and number of entries into the open and closed arms, number of rearing, number of Grooming, number of head dipping [16] and weight of faeces produced. The rectal temperature was taken using a thermometer, immediately after the animal was removed from the EPM apparatus. The percentage of time spent in the different arms was calculated.

\section{Open Field Test}

Developed by Calvin S. Hall, the Open Field (OF) test is an experiment used to assay general locomotory activity levels, anxiety and willingness to explore in rodents in scientific research [17]. It is based on the fact that animals such as rats and mice display a natural aversion to brightly lighted areas. They also have a drive to explore a perceived threatening stimulus. The open field apparatus used in this study was a wooden square box $60 \times 60 \times 40 \mathrm{~cm}$; the floor was divided into 16 smaller squares of equal dimensions (15 $\mathrm{x} 15 \mathrm{~cm}$ ). 
To carry out this experiment, 49 female rats were used and there were distributed into seven groups (as previously describe) of seven rats each. One hour after the administration of the different substances, the animals were placed one after the other in the centre of the open field and observed for five minutes. For each rat, the following parameters were taken center square duration, number of crossing, number of grooming and number of rearing.

\section{Hot Flushes Protocol}

This experiment was carried out with 30 female rats distributed into six groups of five rats each (SHAM, OVX, E2V, RJ100, RJ200 and RJ300). Fourteen days after the introduction of the calibrated data loggers, the animals were treated for three consecutive days, after which they were weighed and dissected. The data loggers were removed, and results printed to a computer. Parameters taken were total number, average duration and frequency of hot flushes.

\section{Statistical Analysis}

The data from each experimental group was expressed as the mean \pm standard error on the mean (S.E.M.). The significance of the difference between OVX group and NOVX group was determined using the unpaired t-test and the significance of the difference between treated groups and OVX group was determined using oneway ANOVA followed by Dunnett's test (Graph Pad Prism, version 5.03). The $p$-value $<0.05$ was considered significant.

\section{Results}

\section{Anxiolytic Effects of Royal Jelly on Rats Subjected to the Elevated Plus Maze Test}

Effects of Royal Jelly on the number of Entries into the Open and Closed Arms of the Elevated Plus Maze: Analysis of the results presented in Figure 1A shows that compared to the SHAM group, ovariectomy induced a non-significant decrease on the number of entries into the open arms of the EPM. At the same time, estrogen depletion induced a significant increase $(p<0.05)$ of this number of entries into the closed arms (Figure 1B), which was $1.60 \pm 0.27$ entries for the SHAM group and $2.83 \pm 0.40$ entries for the OVX group. Just like E2V and DZP, royal jelly at all the tested doses induced a non-significant increase of the number of entries into the open arms (Figure $1 \mathrm{~A}$ ) and a decrease of this parameter in the closed arms (Figure 1B), compared to the OVX group.

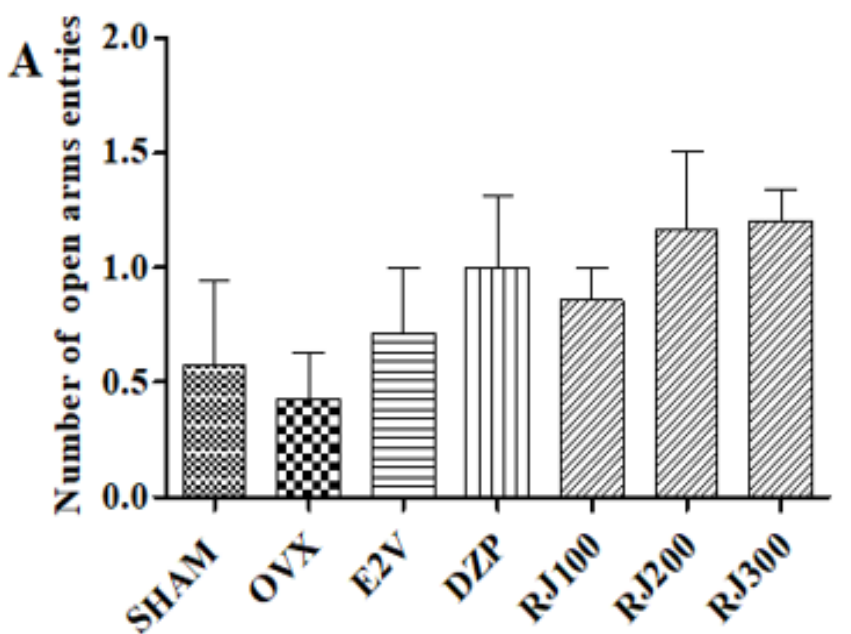

Treatment groups

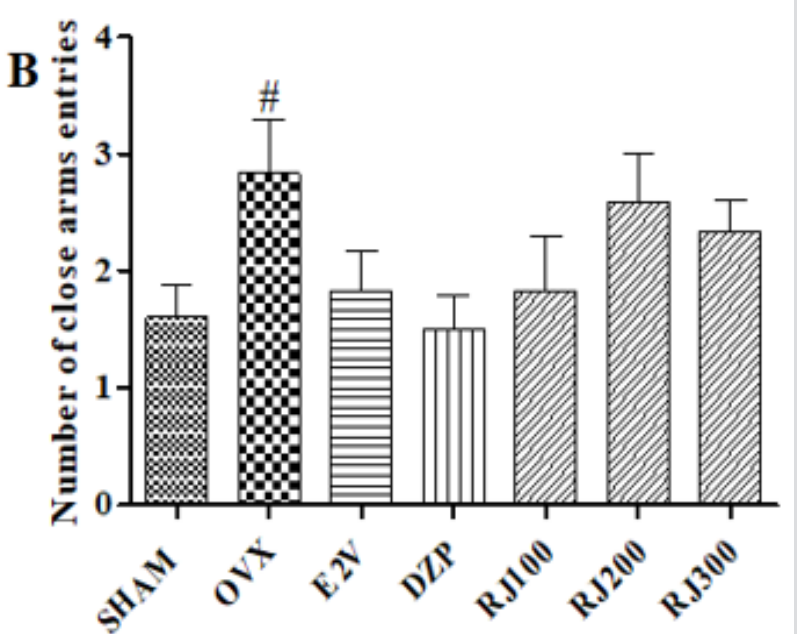

Treatment groups

Figure 1: Effects of royal jelly on the number of entries into the open (A) and closed (B) arms of the elevated plus maze.

Bars represent the number of entries into the open and closed arms of the elevated plus-maze during $5 \mathrm{~min}$. Data are expressed as mean \pm sem, $n=7$ per group. SHAM: Sham operated animals which received distilled water; OVX: Ovariectomised animals treated with distilled water (negative control); E2V: ovariectomised animals treated with estradiol valerate at $1 \mathrm{mg} / \mathrm{kg}$ BW; DZP: ovariectomised animals treated with diazepam at $1 \mathrm{mg} / \mathrm{kg}$ BW; RJ: ovariectomised animals treated with royal jelly at the doses of 100, 200 and 300 $\mathrm{mg} / \mathrm{kg} \mathrm{BW}$.
Effects of Royal Jelly on the Percentage of Time Spent in the Open and Closed Arms of the Elevated Plus Maze: Compared to SHAM groups, ovariectomy induced a significant decrease $(\mathrm{p}<$ 0.05 ) of the percentage of time spent in the open arms (Figure 2A) and a significant increase $(p<0.05)$ of this same parameter in the close arms (Figure 2B) of the EPM. Royal jelly, as well as E2V and DZP induced an increase of the percentage of time spent in the open arms and a decrease of the percentage of time spent in the close arms (Figures 2A \& 2B) compared to OVX group. This effect was significant $(\mathrm{p}<0.05)$ with the DZP treatment. 

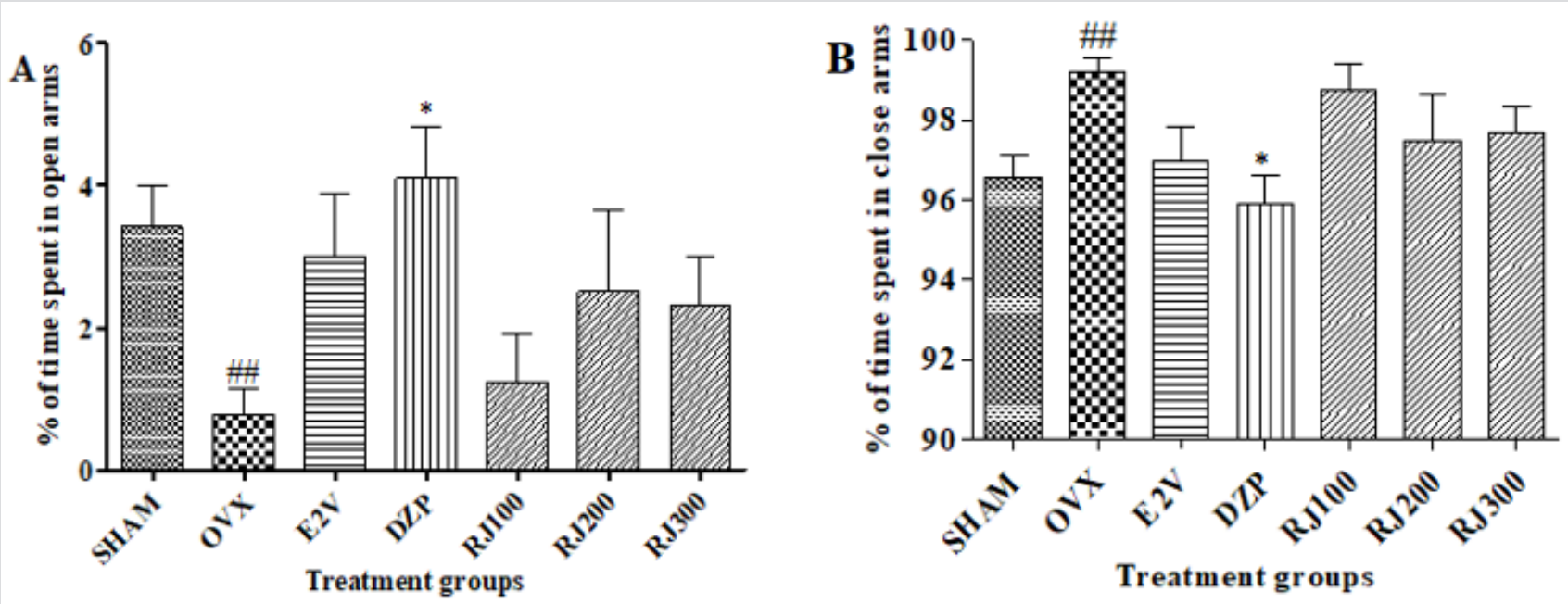

Figure 2: Effects of royal jelly on the percentage of time spent in the open (A) and closed (B) arms of the elevated plus maze.

Bars represent the percentage of time spent in the open and closed arms of the elevated plus-maze during 5 min. Data are expressed as mean \pm sem, $n=7$ per group. SHAM: sham operated animals which received distilled water; OVX: ovariectomised animals treated with distilled water (negative control); E2V: ovariectomised animals treated with estradiol valerate at $1 \mathrm{mg} / \mathrm{kg}$ BW; DZP: ovariectomised animals treated with diazepam at $1 \mathrm{mg} / \mathrm{kg}$ BW; RJ: ovariectomised animals treated with royal jelly at the doses of 100, 200 and $300 \mathrm{mg} / \mathrm{kg}$ BW. \#\# p $<0,01$ vs. SHAM (unpaired t-test); ${ }^{*} \mathrm{p}<$ 0.05 vs. OVX (one-way anova followed by dunnett's test).
Effects of Royal Jelly on the Number of Rearing and Head Dipping

The results presented in Figure 3A show that, ovariectomy induced a significant decrease $(\mathrm{p}<0.001)$ of the number of rearing in the close arms of the EPM compared to the normal control SHAM group. As well as E2V and DZP, royal jelly at all the tested doses induced an increase on the number of rearing compared to the OVX group. This effect was significant ( $p<0.01, p<0.001$ ) with E2V and $\mathrm{RJ}$ at the doses of 200 and $300 \mathrm{mg} / \mathrm{kg} \mathrm{BW}$ (Figure 3A).

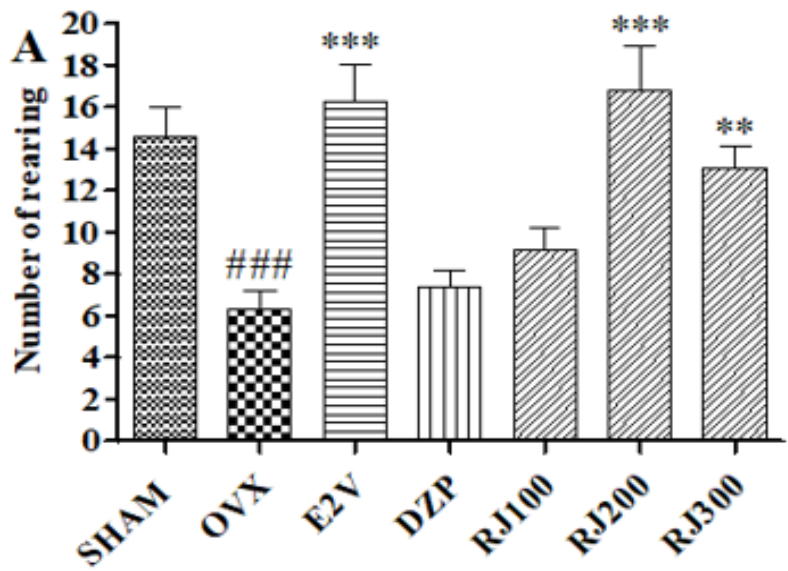

Treatment groups

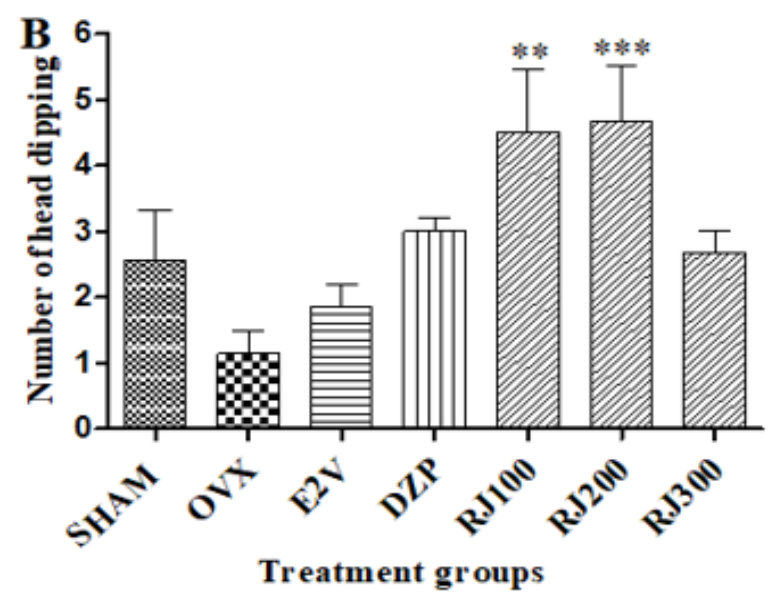

Figure 3: Effects of royal jelly on the number of rearing (A) and head dipping (B) of rats placed on the elevated plus-maze.

Compared to SHAM group, ovariectomy induced a nonsignificant decrease of the number of head dipping in the open arms of the EPM (Figure 3B) which passed from $2.57 \pm 0.75$ for the SHAM group to $1.14 \pm 0.30$ for the OVX group. Royal jelly at all tested doses induced an increase on the number of head-dipping as well as E2V and DZP, compared to OVX (Figure 3B). This effect was significant $(p<0.01, p<0.001)$ with the treatment of RJ at the doses of 100 and $200 \mathrm{mg} / \mathrm{kg} \mathrm{BW}$. 
Bars represent the number of rearing and head dipping of rats placed on the elevated plus-maze during $5 \mathrm{~min}$. Data are expressed as mean \pm sem, $n=7$ per group. SHAM: sham operated animals which received distilled water; OVX: ovariectomised animals treated with distilled water (negative control); E2V: ovariectomised animals treated with estradiol valerate at $1 \mathrm{mg} / \mathrm{kg} \mathrm{BW}$; DZP: ovariectomised animals treated with diazepam at $1 \mathrm{mg} / \mathrm{kg}$ BW; RJ: ovariectomised animals treated with royal jelly at the doses of 100, 200 and 300 $\mathrm{mg} / \mathrm{kg}$ BW. \#\#\# p $<0.01$ vs. SHAM (unpaired t-test); ${ }^{* *} \mathrm{p}<0.01$, *** $\mathrm{p}<0.001$ vs. OVX (one-way anova followed by dunnett's test).

\section{Effects of Royal Jelly on the Number of Grooming, Weight of}

\section{Faeces Produced and on Rectal Temperature}

As shown in Figure 4A, estrogen depletion induced a significant increase $(\mathrm{p}<0.05)$ of the number of grooming in the EPM, compared to SHAM group. As well as E2V and DZP, royal jelly at the dose of $300 \mathrm{mg} / \mathrm{kg}$ BW induced a non-significant decrease of the number of grooming compared to OVX group (Figure 4B). This number of grooming passed from $5.00 \pm 0.81$ for the OVX group to $3.33 \pm 0.52$ for RJ at the dose of $300 \mathrm{mg} / \mathrm{kg} \mathrm{BW}$.

Analysis of the results presented in Figure 4B, show that compared to SHAM group, ovariectomy induced a significant increase $(\mathrm{p}<0.05)$ of the weight of faeces. Same as E2V and DZP, royal jelly at all the tested doses induced a significant decrease ( $p<0.01, p<0.001$ ) of the weight of faeces produced in the EPM compared to the OVX group (Figure 4B).

The results presented in Figure 4C show that ovariectomy induced a significant increase $(\mathrm{p}<0.05)$ of the rectal temperature compared to SHAM group, which passed from $37.81 \pm 018^{\circ} \mathrm{C}$ for the SHAM group to $38.31 \pm 0.11^{\circ} \mathrm{C}$ for OVX group. Compared to OVX group, the treatment with RJ as well as E2V and DZP induced a decrease of rectal temperature. This effect was significant $(\mathrm{p}<0.05)$ with the treatment of RJ at the doses of 200 and $300 \mathrm{mg} / \mathrm{kg} \mathrm{BW}$ and DZP.
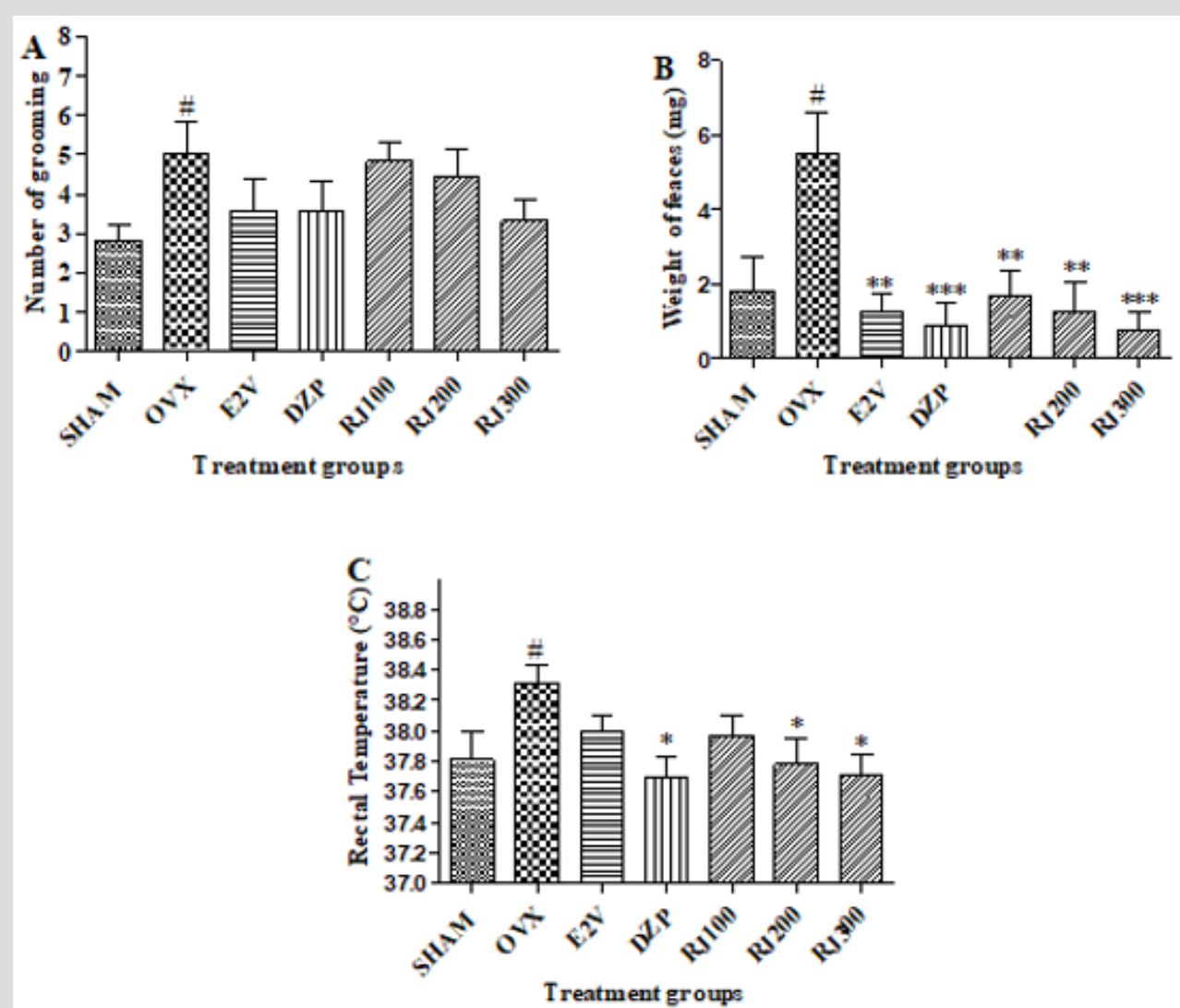

Figure 4: Effects of royal jelly on the number of grooming (A), Weight of feaces produced (B) and rectal temperature (C) of rats placed on the elevated plus-maze.

Bars represent the number of grooming, Weight of feaces produced and rectal temperature of rats placed on the elevated plus-maze during 5 min. Data are expressed as mean \pm sem, $n=7$ per group. SHAM: sham operated animals which received distilled water; OVX: ovariectomised animals treated with distilled water (negative control); E2V: ovariectomised animals treated with estradiol valerate at $1 \mathrm{mg} / \mathrm{kg}$ BW; DZP: ovariectomised animals treated with diazepam at $1 \mathrm{mg} / \mathrm{kg} \mathrm{BW}$; RJ: ovariectomised animals treated with royal jelly at the doses of 100,200 and $300 \mathrm{mg} / \mathrm{kg} \mathrm{BW}$. $\# \mathrm{p}<0.05$ vs. SHAM (unpaired t-test); ${ }^{*} \mathrm{p}<0.05$, ** $\mathrm{p}<0.01,{ }^{* * *} \mathrm{p}<$ 0.001 vs. OVX (one-way anova followed by dunnett's test). 
Anxiolytic Effects of Royal Jelly on Rats Subjected to the Open Field Test

Effects of Royal Jelly on Center Square Duration and Number of Crossing: The results presented in Figure 5A shows that ovariectomy induced a non-significant decrease of the time spent at the center of the open field compared to the SHAM group (passed from $2.00 \pm 0.69 \mathrm{~s}$ for the SHAM group to $1.14 \pm 0.26 \mathrm{~s}$ for the OVX group). Royal jelly, as well as E2V and DZP induced an increase on the time spent at the centre of the OF compared to OVX. This effect was significant $(\mathrm{p}<0.05)$ with the RJ treatment at the doses of 100 and $300 \mathrm{mg} / \mathrm{kg} \mathrm{BW}$.
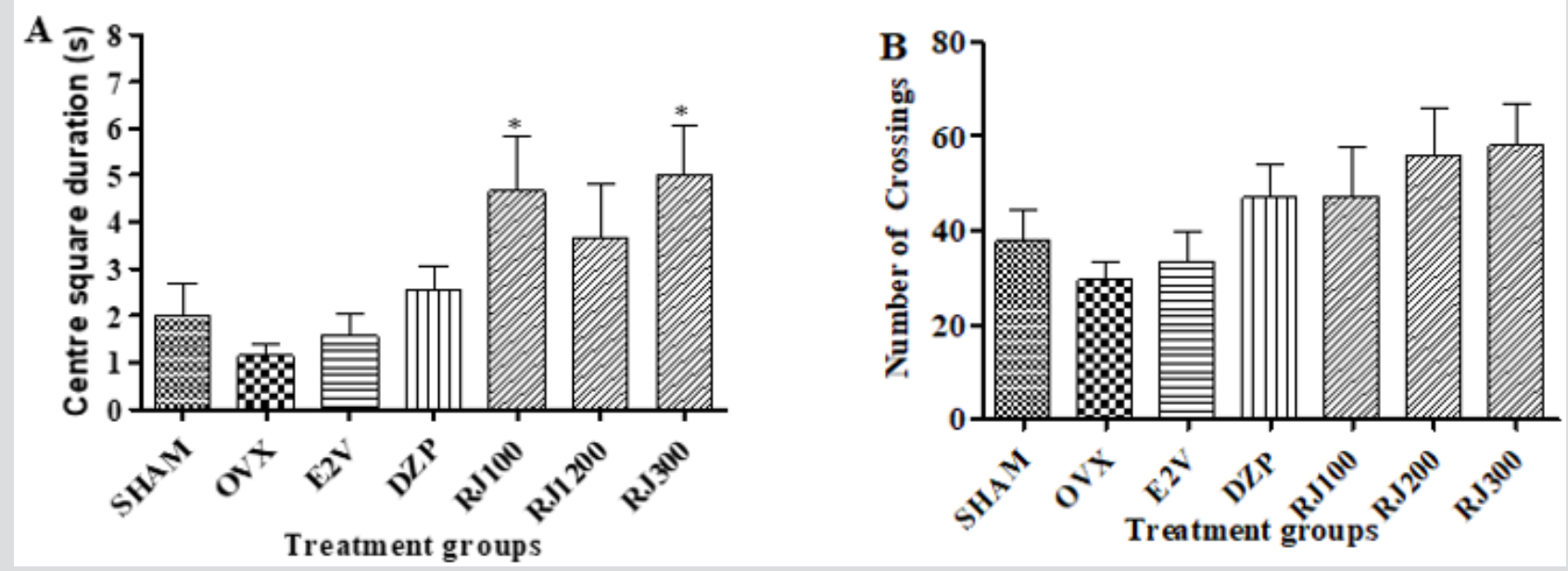

Figure 5: Effects of royal jelly on the centre square duration (A) and number of crossing (B) of rats placed on the open field.

The analysis of the results presented in Figure $5 \mathrm{~B}$ shows that estrogen depletion induced a non-significant decrease of the number of crossing, compared to the SHAM group (passed from $37.79 \pm 6.47$ crossing from the SHAM group to $29.57 \pm 4.02$ crossing for OVX group). Estradiol, diazepam and Royal jelly at all the tested doses induced a non-significant increase of the number of crossing (passed from $29.57 \pm 4.02$ crossing for the OVX group to $47.31 \pm 10.42,55.97 \pm 9.95$ and $58.0 \pm 8.68$ crossing respectively for $\mathrm{RJ}$ at the doses 100, 200 and $300 \mathrm{mg} / \mathrm{kg}$ BW) respectively.
Bars represent the centre square duration and number of crossing of rats placed on the open field during $5 \mathrm{~min}$. Data are expressed as mean \pm sem, $n=7$ per group. SHAM: sham operated animals which received distilled water; OVX: ovariectomised animals treated with distilled water (negative control); E2V: ovariectomised animals treated with estradiol valerate at $1 \mathrm{mg} / \mathrm{kg}$ BW; DZP: ovariectomised animals treated with diazepam at $1 \mathrm{mg} /$ kg BW; RJ: ovariectomised animals treated with royal jelly at the doses of 100, 200 and $300 \mathrm{mg} / \mathrm{kg} \mathrm{BW.} \mathrm{*p}<0.05$ vs. OVX (one-way anova followed by dunnett's test).

\section{Effects of Royal Jelly on the Number of Grooming and Rearing}

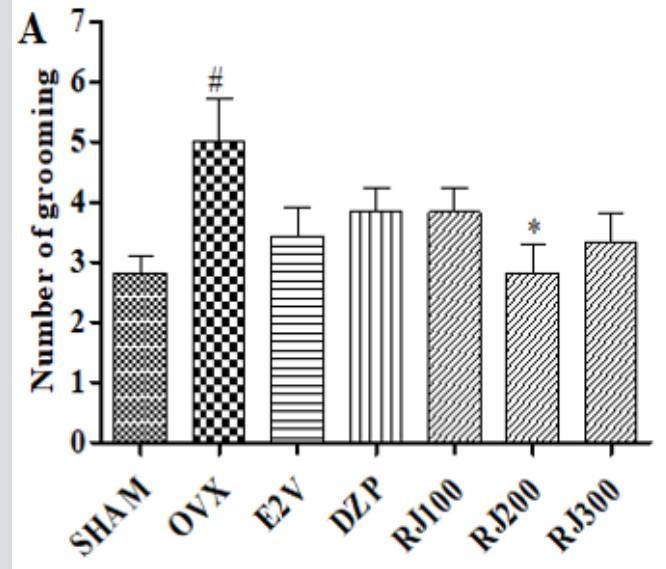

Tr eatment groups

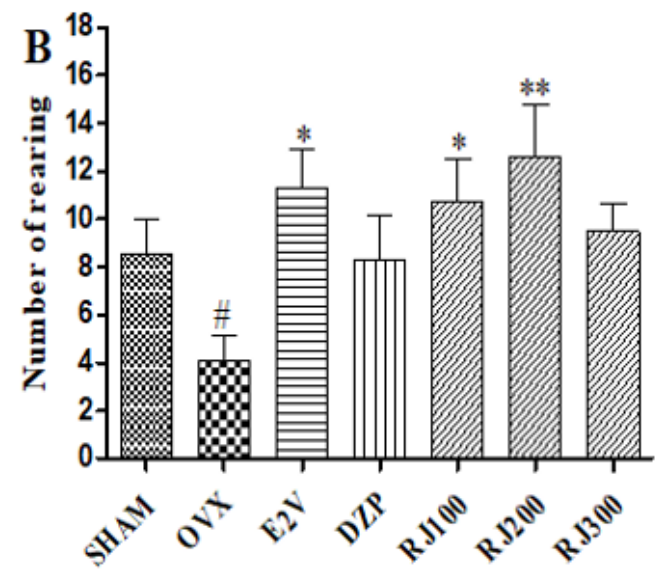

Treatment groups

Figure 6: Effects of royal jelly on the number of grooming (A) and rearing (B) of rats placed on the open field. 
As presented in Figure 6A, ovariectomy induced a significant increase of the number of grooming $(p<0.05)$, compared to the SHAM group. Royal jelly, as well as E2V and DZP, induced a decrease of the number of grooming, compared to OVX group (Figure 6A). This effect was significant $(\mathrm{p}<0.05)$ with RJ treatment at the dose of $200 \mathrm{mg} / \mathrm{kg} \mathrm{BW}$. The results presented in Figure 6B shows that estrogen depletion induced a significant decrease $(\mathrm{p}<0.05)$ of the number of rearing in the OF, compared to the SHAM group. Compared to OVX, royal jelly induced an increase of the number of rearing in the OF, as well as E2V and DZP (Figure 6B). This effect was significant $(\mathrm{p}<0.05, \mathrm{p}<0.01)$ with the RJ treatment at the doses of 100 and $200 \mathrm{mg} / \mathrm{kg} \mathrm{BW}$ and E2V treatment.

Bars represent the number of grooming and rearing of rats placed on the open field during $5 \mathrm{~min}$. Data are expressed as mean \pm sem, $\mathrm{n}=7$ per group. SHAM: sham operated animals which received distilled water; OVX: ovariectomised animals treated with distilled water (negative control); E2V: ovariectomised animals treated with estradiol valerate at $1 \mathrm{mg} / \mathrm{kg}$ BW; DZP: ovariectomised animals treated with diazepam at $1 \mathrm{mg} / \mathrm{kg}$ BW; RJ: ovariectomised animals treated with royal jelly at the doses of 100,200 and $300 \mathrm{mg} / \mathrm{kg} \mathrm{BW}$. $\# \mathrm{p}<0.05$ vs. SHAM (unpaired t-test); ${ }^{*} \mathrm{p}<0.05,{ }^{* *} \mathrm{p}<0.01$ vs. OVX (one-way anova followed by dunnett's test).

\section{Effect of Royal Jelly on Hot Flushes}

Effects of Royal Jelly on the Total Number and Average

\section{Duration of Hot Flushes}

The analysis of the results in Figure 7A shows that ovariectomy induced a non-significant increase in the total number of hot flushes compared to SHAM group (passed from $42.80 \pm 8.24$ hot flushes for the SHAM group to $57.20 \pm 7.55$ hot flushes for the OVX group). Comparing to the OVX group, royal jelly induced a decrease in the total number of hot flushes at all the tested doses (passed from $57.20 \pm 7.55$ hot flushes for the OVX group to $48 \pm 5.70,45.60 \pm 5.61$ and $43 \pm 2.28$ hot flushes for RJ treatment at the doses 100, 200 and $300 \mathrm{mg} / \mathrm{kg}$ BW respectively) (Figure 7A). Estradiol valerate also induced a non-significant decrease of this parameter, compared to OVX group.
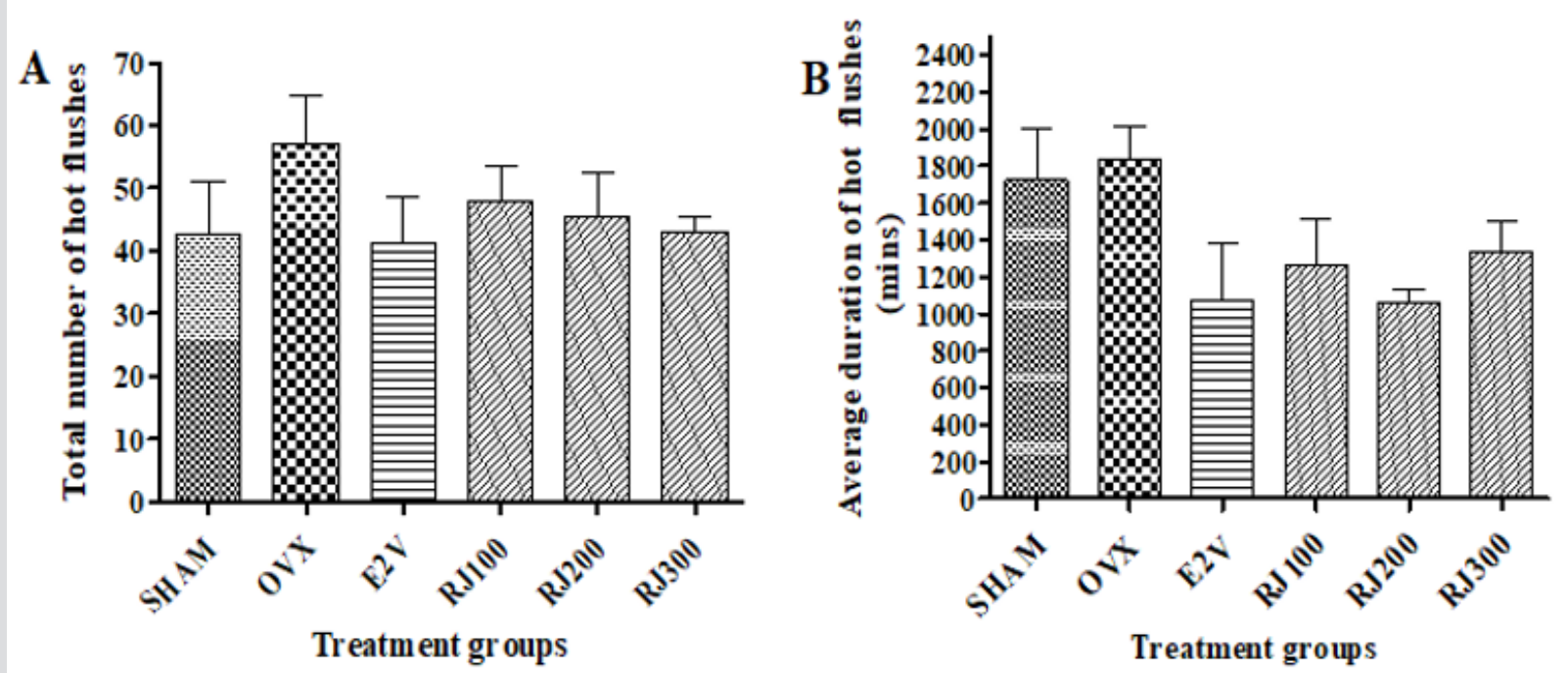

Figure 7: Effects of royal jelly on the total number (A) and average duration (B) of hot flushes in ovariectomised wistar rats.

The results presented in Figure 7B show that ovariectomy induced a non-significant increase in the average duration of hot flushes, compared to the SHAM group. The estradiol valerate as well as royal jelly treatments induced a non-significant decrease of this average duration compared to the OVX group. The average duration of hot flushes passed from $1837.50 \pm 180.35$ for the OVX group to $1267.20 \pm 243.49,1063.25 \pm 69.75$ and $1335.50 \pm 164.30$ for the royal jelly treatment at the doses of $100,200,300 \mathrm{mg} / \mathrm{kg} \mathrm{BW}$ respectively.

Bars represent the total number and average duration of hot flushes. Data are expressed as mean \pm sem, $n=5$ per group. SHAM: sham operated animals which received distilled water; OVX: ovariectomised animals treated with distilled water (negative control); E2V: ovariectomised animals treated with estradiol valerate at $1 \mathrm{mg} / \mathrm{kg}$ BW; RJ: ovariectomised animals treated with royal jelly at the doses of 100, 200 and $300 \mathrm{mg} / \mathrm{kg}$ BW.

\section{Effects of Royal Jelly on the Frequency of Hot Flushes}

Comparing to the SHAM group, ovariectomy induced an increase of the frequency of hot flushes at the intervals $6,24,30,36$, $42,48,60$ and $66 \mathrm{~h}$ (Figure 8A-8D). This effect of estrogen depletion was significant $(p<0,01 ; p<0,05)$ at the intervals 48 and $66 \mathrm{~h}$. the treatment with royal jelly, as well as E2V, induced a decrease of the frequency of hot flushes compared to OVX group (Figure 8B-8D). This effect was significant $(\mathrm{p}<0.05)$ at the interval $24 \mathrm{~h}$ with the RJ at the dose of $200 \mathrm{mg} / \mathrm{kg} \mathrm{BW}$ (Figures 8C). 

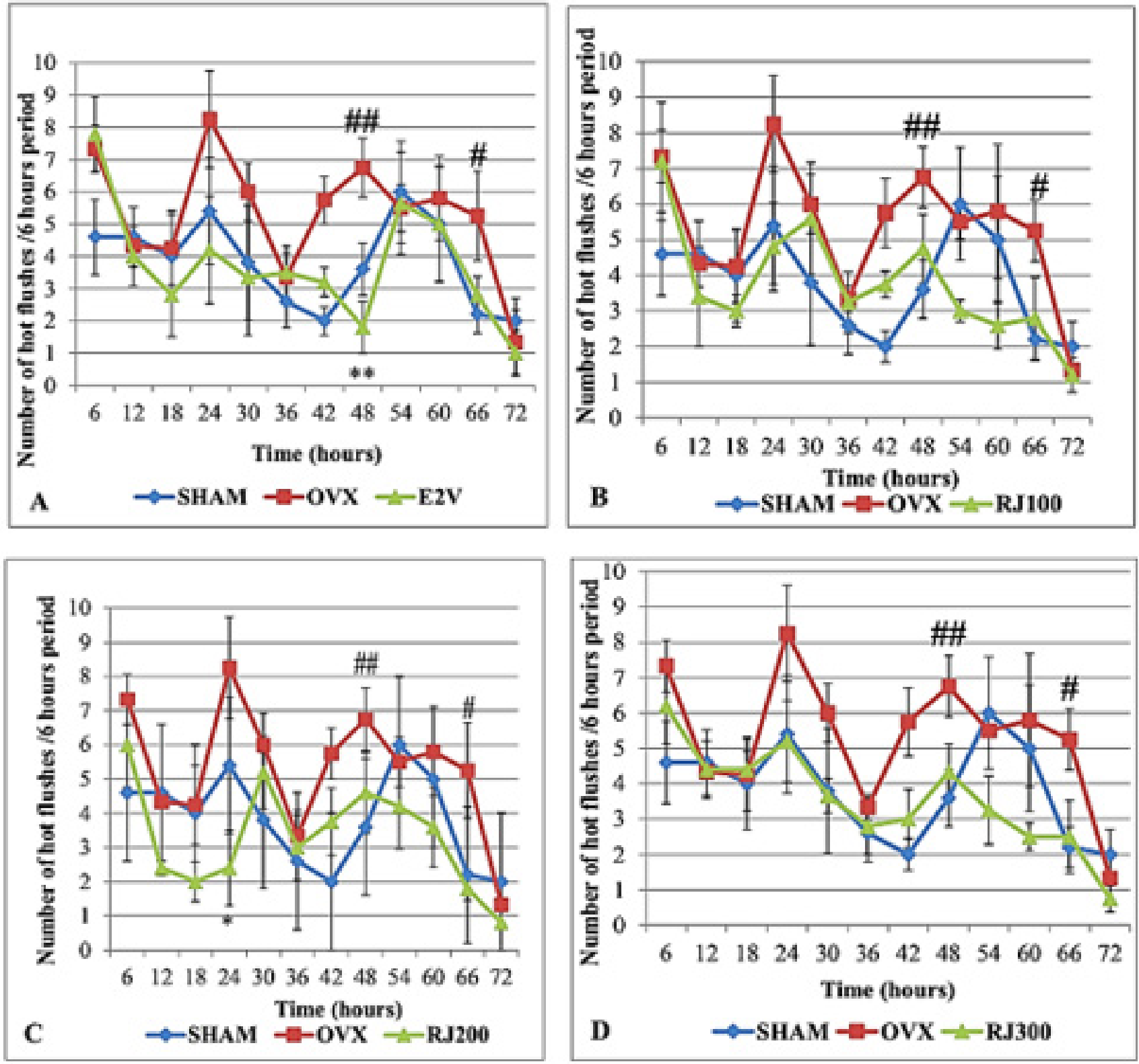

Figure 8: Effects of royal jelly on the frequency of hot flushes in ovariectomised wistar rats.

Curves represent the frequency of hot flushes. Data are expressed as mean \pm sem, $n=5$ per group. SHAM: sham operated animals which received distilled water; OVX: ovariectomised animals treated with distilled water (negative control); E2V: ovariectomised animals treated with estradiol valerate at $1 \mathrm{mg} / \mathrm{kg}$ BW; RJ: ovariectomised animals treated with royal jelly at the doses of 100, 200 and $300 \mathrm{mg} / \mathrm{kg} \mathrm{BW.} \mathrm{\#} \mathrm{p}<0.05$, \#\# p $<0.01$ vs. SHAM (unpaired t-test); * $\mathrm{p}<0.05,{ }^{* *} \mathrm{p}<0.01$ vs. OVX (one-way anova followed by dunnett's test).

\section{Discussion}

According to the World Health Organization [4], anxiety is the most common psychiatric disorder and it significantly affects quality of life. At menopause, neurological changes at the level of the brain are responsible for many disorders amongst which are anxiety and mood disorder. The results obtained in our investigation with the EPM test showed that compared to SHAM group, ovariectomy induced an increase in the number of entries into the closed arms and the percentage of time spent in the same arms. In the open arms, a decrease in the same parameters were observed. All these effects reflect a decrease of open arms exploration and showed the anxiogenic responses of ovariectomy in the elevated plus maze [18]. These anxiogenic effects of ovariectomy were also materialized by a decrease in the number of rearing and head dipping and an increase on the number of grooming, the weight of faeces produced and the rectal temperature. The Wistar rats that were treated with royal 
jelly, as well as E2V and DZP, showed an increase in the number of entries and percentage of time spent in the open arms compared with those of the OVX group. They equally showed reduced number of closed arms entries and percentage of time spent in these arms. According to Ketcha \& Oviedo et al. [19,20], anxiolytic compounds are able to induce an increase of activity in the open arms of EPM. This effect directly reflects a reduction of anxiety. The reduction in the activities of the closed arms of EPM also shows a decrease of stress. These parameters observed at the same time in the open and closed arms probably means that royal jelly may be endowed with anxiolytic properties as suggested by Ngo Bum et al. [21].

The treatment with royal jelly, as well as E2V and DZP, also induced an increase in the number of rearing and head dipping. Moreover, royal jelly induced a decrease on the number of grooming, the weight of faeces produced and the rectal temperature. These results reflect an increase of locomotory activities and anxiolytic effects of royal jelly. Anxiety evaluated by the open field showed that ovariectomy induced a decrease on the time spent at the centre of the OF, as well as the number of crossing and rearing, and an increase in the number of grooming compared to the SHAM group. The treatment with royal jelly, as well as E2V and DZP, equally led to an increase on the centre square duration, number of crossing and rearing compared to OVX group. The treatment with RJ also induces a decrease of the number of grooming. As demonstrated by Ketcha et al. and Ngo Bum et al. [20,21] substance that increases locomotory activity, in stress condition as in the case of open field test has anxiolytic effects. These results confirm the anxiolytic effects of RJ observed in the EPM test. According to Anuradha et al [22], drugs of natural origin can be useful in stress-induced anxiety. The anxiolytic properties of royal jelly could result from its action as selective ER modulators [23]. It is known that anxiety behaviour increase the deficiency of ER $\beta$ in female mice [24]. Royal jelly could act through the ER $\beta$ because according to Lund et al. [25], estrogens and oestrogenic substances carry out their anxiolytic properties through this partway. Such as many other anxiolytic substances, RJ could act as agonist of Gamma Amino-Butyric Acid (GABA) on GABA receptors [26]. Royal jelly can also act as antagonist of N-Methyl-DAspartic Acid (NMDA) [27] and 5- Hydroxytryptamine (5-HT) by binding to their receptors [28].

The results obtained on evaluation of hot flushes show that ovariectomy induced an increase on the total number and average duration of hot flushes compared to SHAM group. The administration of E2V for three consecutive days, compared to OVX group, led to a decrease in the total number, average duration and frequency of hot flushes. These results confirm previous studies which explained that estrogen depletion causes hot flushes which can be reversed by hormone replacement therapies [29,30]. After three days treatment with royal jelly at all the tested doses, as well as $\mathrm{E} 2 \mathrm{~V}$, there was a decrease on the total number, average duration and frequency of hot flushes compared to OVX group. These effects could be due to the action of royal jelly on estrogen receptors in the brain. As suggested by Zingue et al. [31] substance with estrogenic effect like Ficus umbellate can act on estrogen receptor to reverse the thermoregulatory disorder caused by post ovariectomy depletion of endogenous estrogen. Given the fact that hot flushes at menopause are directly linked to anxiety, it will be of great importance to compare the results obtained from hot flushes and those from anxiety behavior.

According to these results, the untreated ovariectomised animals apart from being too anxious, showed increase in the total number, average duration and frequency of hot flushes. This is because the lack of oestrogens modifies the activity of neurotransmitters especially that of serotonin and noradrenalin, which are neurotransmitters involved in the regulation of central temperature and behavior [30]. The administration of estradiol valerate reduced at the same time anxiety and hot flushes, confirming the reports that suggest that hormone replacement suppresses hot flushes and menopause induced anxiety. Just like estradiol, royal jelly at all the tested doses and most at the dose of $200 \mathrm{mg} / \mathrm{kg}$ BW reduced hot flushes and menopause related anxiety, in nearly all the parameters in the two behavioral test. These results show that royal jelly is capable of regulating temperature and behavioral systems.

\section{Conclusion}

The aim of this study was to evaluate the effects of royal jelly on anxiety and hot flushes in ovariectomised rats. Our findings have shown that RJ exhibits anxiolytic properties and reduces the total number average duration and frequency of hot flushes. These results suggest that royal jelly is capable of reversing some disorders related to estrogen depletion induced by ovariectomy. The dose of $200 \mathrm{mg} / \mathrm{kg}$ BW showed the most beneficial effects on anxiety and hot flushes. Royal jelly could be considered as a safer health alternative product to relief anxiolytic menopausal symptoms. These anxiolytic effects and hot flushes prevention by royal jelly could justify it traditional use by older women.

\section{References}

1. Takahashi T, Johnson K (2015) Menopause. Med Clin North Am 99: 521534.

2. Sievert L (2006) Menopause biocultural perspective. Medical Anthropology Quarterly 21: 414-416.

3. Freedman RR, Norton D, Woodward S, Cornelissen G (1995) Core body temperature and circadian rhythm of hot flashes in menopausal women. J Clin Endocrinol Metab 80: 2354-2358.

4. World Health Organization (2008) Traditional medicine. Fact sheet 134 2003-05.

5. Bromberger JT, Kravitz HM, Chang Y, Randolph JF, Gold EB (2013) Does risk of anxiety increase during the menopausal transition? Study of women health across the nation. Menopause 5: 481-482.

6. Freeman EW, Sammel MD, Sanders RJ (2014) Risk of long-term hot flashes after natural menopause: Evidence from the Penn ovarian aging study cohort. Menopause 21: 924-932.

7. Albertazzi P (2007) Non-estrogenic approaches for the treatment of climacteric symptoms. Climacteric 10: 115-120. 
8. Colditz GA (2005) Estrogen, estrogen plus progestin therapy, and risk of breast cancer. Clin Cancer Res 11: 909-917.

9. Ito K (2007) Hormone replacement therapy and cancers: The biological roles of estrogen and progestin in tumorigenesis are different between the endometrium and breast. Tohoku J Exp Med 212: 1-12.

10. Scheid V (2007) Traditional Chinese medicine -what are we investigating? The case of menopause. Complementary Therapies in Medicine 15: 54-68.

11. Doyle BJ, Frasor J, Bellows LE, Locklear TD, Perez A, et al. (2009) Estrogenic effects of herbal medicines from costa rica used for the management of menopausal symptoms. Menopause 16: 748-755.

12. Mozafar K, Atefe A, Elham G (2017) New findings on biological actions and clinical applications of royal jelly: A review. J Diet Suppl 15: 757-775.

13. Mishima S, Suzuki KM, Isohama Y, Kuratsu N, Araki Y, et al. (2005) Royal jelly has estrogenic effects in vitro and in vivo. J Ethnopharmacol 101 215-220.

14. Lane NE, Yao W, Kinney JH, Modin G, Balooch M, et al. (2003) Both hPTH(1-34) and bFGF increase trabecular bone mass in osteopenic rats but they have different effects on trabecular bone architecture. J Bone Miner Res 18: 2105-2115.

15. OECD (2007) Third meeting of the validation management group for the screening and testing of endocrine disrupters (mammalian effects).

16. Casarrubea M, Magnusson MS, Roy V, Arabo A, Sorbera F, et al. (2015) Temporal patterns of rats behavior in the elevated plus maze comparative analysis between male subjects of strains with different basal levels of emotionality. J Neurosci Methods 268: 007-024.

17. Hall C, Ballachey E (1932) A study of the rat's behavior in a field A contribution to method in comparative psychology University of California. Publications in Psychology 6: 1-12.

18. Zemo GF, Djiogue S, Ketcha GJM, Seke E, Yonkeu T, et al. (2017) Fourteen days post-ovariectomy estrogens decline is associated with anxiogenic effects on wistar rats. Journal of Pharmacy and Pharmacology 5: 869876.

19. Oviedo VM, Milded GG, Rincon J, Guerrero MF (2006) Effect of an extract of Annona muricata on central nervous system. Pharmacology online 3 : 342-347.

\section{ISSN: 2574-1241}

DOI: 10.26717/BJSTR.2019.19.003356

Djiogue Sefirin. Biomed J Sci \& Tech Res

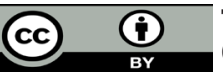

This work is licensed under Creative

Commons Attribution 4.0 License

Submission Link: https://biomedres.us/submit-manuscript.php
20. Ketcha WG JM, Zemo GF, Djiogue S, Awounfack CF, Njamen D (2017) Estrogenic and anxiolytic effects of the decoction of stem bark of Khayaanthotheca (Welw.) C.D C (Meliaceae) in ovariectomised Wistar rats. International Journal of Phytomedicine 9: 241-252.

21. Ngo Bum E, Taiwe GS, Moto FC O, Ngoupaye GT, Nkantchoua GC N, et al. (2009) Anticonvulsant, anxiolytic and Sedative properties of the roots of Nauclealatifolia in Mice. Epilepsy and Behavior 15: 434-440.

22. Anuradha H, Srikumar BN, Shankaranarayana BS, Lakshmana M (2008) Euphorbia hirta reverses chronic stress-induced anxiety and mediates its action through the G.ABA(A)benzodiazepine Receptor-Cl- channel complex. Journal of Neural Transmission 115: 35-42.

23. Suzuki KM, Isohama Y, Maruyama H (2008) Estrogenic activities of fatty acids and sterol isolated from royal jelly. Evid Based Complement Alternat Med 3: 295-302.

24. Imwalle DB, Gustafsson JÅ, Rissman EF (2005) Lack of functional estrogen receptor $\beta$ influences anxiety behavior and serotonin content in female mice. Physiology and Behavior 1: 157-163.

25. Lund TD, Rovis T, Chung WC, Handa RJ (2005) Novel actions of estrogen receptor-on anxiety-related behaviors. Endocrinology 146: 797-807.

26. Xiu-Yan W, Jing-Yu Y, Jim-Hui W, Chun-Fu W (2007) Anxiolytic effect of saponins from Panaxquinquefolium in mice. J Ethnopharmacol 111 613-618.

27. Olivier B, Zethof T, Pattij T, van Boogaert M, Van Oorschot R, et al. (2003) Stress induced hyperthermia and anxiety: Pharmacological validation. Eur J Pharmacol 463: 117-132.

28. Graeff FG (2007) Serotonin, the periaqueductal gray and panic. Neurosci Biobehav Rev 28: 239-259.

29. Santoro N (2008) Symptoms of menopause: Hot flushes. Clin Obstet Gynecol 51: 539-548.

30. Shanafelt MD, Debra L, Barton RN, Alex A, Adjei MD, et al. (2002) Pathophysiology and treatment of hot flashes. Mayo Clin Proc 77: 12071218.

31.Zingue S, Thomas M, Tchatchou, Magne NC, Winter E, et al. (2016) Estrogenic effects of ficus umbellate vahl. (Moraceae) extracts and their ability to alleviate some menopausal symptoms induced by ovariectomy in Wistar rats. J Ethnopharmacol 179: 332-344.

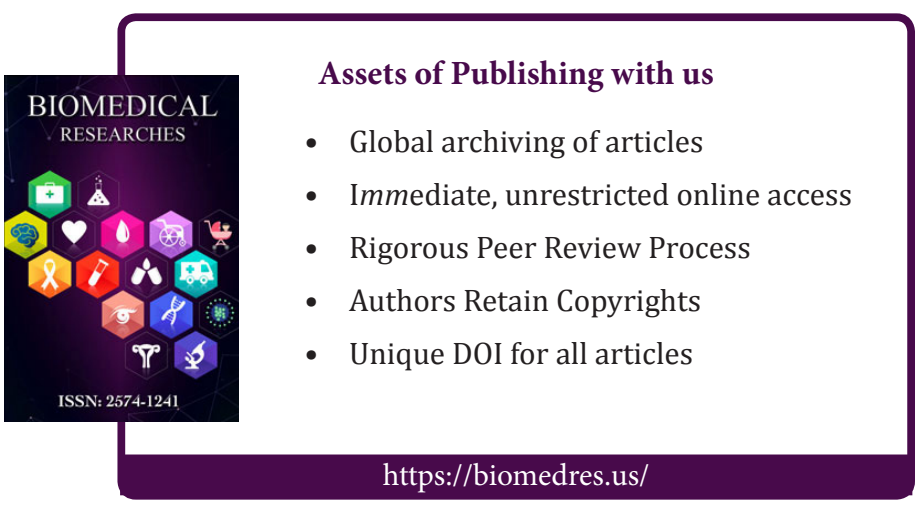

